\title{
Effect of TV Fashion Shows on Dressing Style of Female Students of University Of Gujrat
}

\author{
${ }^{1}$ SaimaZareen, ${ }^{2}$ Dr Arshad Ali, ${ }^{3}$ Saira Shafi \\ ${ }^{1,2,3}$ Department of Communication Studies and Media Center, University of Gujrat,, Pakistan
}

\begin{abstract}
This study examines and reveals the "Effects of fashion shows of TV channels on the dressing style of female students at the University of Gujrat". People deal with fashion every day and also become crazy for fashion. According to Crane (2000) clothes are the key factor which can make or destroy one's personality. Today each person wants to look perfect; for this he or she adopt fashion from fashion magazines, TV ads, TV dramas, fashion shows, TV personalities or peer groups. Total 150 female students was selected as a sample from the whole population for investigating does really female students of University of Gujrat are involve in fashion from TV fashion shows and become fashion conscious. Researcher adopts quantitative method for investigating problem and conduct survey through questionnaire for measuring results. At the end of the research, results and conclusion revels that the female students of University of Gujrat like to wear indo western dresses, combination of western and Pakistani dress.
\end{abstract}

\section{Introduction}

Everyone wants to look perfect and each girl always wants to be a fabulous from others. Whether current or past time, fashion always been involved in women's lives; she always keeps looking for new ways which introduced new fashion. Well dressing is a big part of beauty, it's not only reflect one's personality but also represents the glow of beauty because if any one's facial features are not attractive, figure is not slim, skin color is not fair or not have ideal height then trendy apparels can cover these defects(Berger, n.d.).

Fashion in apparel is a process in which old fashion is presented in a new look. TV, fashion shows and magazines are the major factors which change apparel of teenage girls (Kiran, Riaz, Malik, 2002, p. 378). Obviously, the modern era is the era of globalization; in which media has made the earth as a global village, it removes the distance. All types of media provide you each and every necessary updates regarding your favorite topic .

\section{History of Fashion}

The history of clothing is very old; it started since the era of Adam and Eva. The style of body covering is change in each period, this changing become fashion. In the beginning of $20^{\text {th }}$ century, after the invention of sewing machine and other technologies the clothes appear in new form (Wikipedia, n.d.).

After the concept of fashion took places it provide a way for promoting something new, which doesn't exist before form it or which comes with something new or unusual dresses. It is generating its effects since the first fashion show was held in history. Now a day, every one can see fashion shows staying at home through TV channels; it not only grabs the attention of women but also drawn the attention of girls towards the fashion shows and made them fashion conscious. According to Wikipedia (n.d.) fashion shows introduced designers and brands of apparel.

\section{Research Question:}

To accomplish the aim and purpose of this study, researcher has formulated some research questions. RQ1: Do fashion shows of TV channels promote different dressing style among the female students of UOG? RQ2: Do UOG female students adopt the dressing style that appears in TV fashion show?

\section{Research Hypothesis}

$\mathrm{H}_{0} 1$ : These TV channels don't promote different dressing styles among female students of UOG.

\section{Objectives of the Study}

Indian and western cultures are gradually making its place in Pakistani culture. Pakistani fashion shows of these TV channels are playing a vital role. Girls of all age groups are widely affected by fashion shows; they become crazy when they watch a fashion show flooded with new dresses. The aim of this research is

- To find out the reason for adopting new fashion apparel.

- To find out the effects of these fashion shows on our culture. 
- To investigate that fashion apparel are only adopted by the elite or middle class female students of UOG...... victim of fashion apparel.

- To find out the factors that brings change in the dressing style.

- To find out the views of UOG female students regarding promotion of the new dress designs.

\section{Significance of the Study}

The aim of the study is to find out the effects of the fashion shows which appear on TV channels. This kind of study was not conducted before. Through this research, the findings will reveal how many female students of UOG follow the fashion depicted through fashion shows.

\section{Literature Review}

Twenty to twenty five years ago, fashion industry was not stable in Pakistan. But now it has been put a great influence on the women of Pakistan especially on the female students. If there is any social, religious or academic event everyone wants to wear trendy clothes, branded apparel because media has made them fashion conscious person who want to move with fashion either they can afford it or not.

\section{Definition of Fashion}

The word fashion refers to the meaning of new, in, popular stylish designs for dresses, hair or other accessories for decorating personality (Oxford, 2010). Which type of apparel is currently in and huge population wear it, is call fashion (Nirmala, 2008).

Fashion never remains in its original form, its change or modify with time and place; if it remain without any modification then noting will be introduced as a "new" style (Chanel, n.d.). Fashion is sometimes imprisonment. Which people have themselves imposed on them, while they know, they feel comfortable without much in fashion.

When a product is widely spread among the people, people adopt it on large scale and you observe that it was not seen before, is known as fashion; its change immediately of latter because both people and eyes don't want to see the same thing is repeated (Noubikko, n.d.).

\section{Definition of Media}

The word media refers to the meaning of main sources of communication; these can be in the form of written, visuals with narrations or written plus clips or images (Oxford, 2010).

According to Yourdictionary.com (n.d.) the ways that can interact with the large number of people in a single moment is called mass media. Mass media is use to shape the opinions, views, impact, thought, impression or message of it audience, either the audience is broad or limited (Mcdermott, \& Albrecht, 2002).

\section{Definition of Television}

The world television refers to the meaning of a system which alters the visuals and sounds into the electronic signals and then people can see the combination of visual and sound on the screen (Oxford, 2012).

All mediums of mass media have a significant effect on the lives of audience but no one has a power like television (Porter, n.d.).According to Characteristics of television as a medium (n.d., p. 17) television has both visuals and sounds, which makes television different from other mediums. Moreover, on this, people can see everything which they want without going anywhere; means people can see cricket, movies or other shows at home without investing money on tickets (p. 18).Through this medium people see different channels on screen, which frame the minds of people for adopting the culture of others (Baloch, 2011). She continues, television also leave long lasting effects in the shape of fashion, emotion, mental disturbance and fear.

\section{Role of media in fashion world}

In present media is involve in everything; either it's create ways for lunching something or play a role in destroying anything. According to "Media in fashion", today is the world of media; few decades ago, fashion was not so much popular among the peoples but now it makes it place in the field of media and know it has established as a big industry, it provides awareness about the latest trendy fashion among the people through print, electronic and now digital media.McFatter (2005, May) conducted study for measuring the number women of United Kingdom who become fashion addicted and he found that large number of women adopt different fashions through media like TV shows, movies, magazines, etc. According to Zeb, Rashid \& Bilal, (2011, p. 225) there was an era when people want to wear their traditional dresses like salwarkameez; obviously today people were salwarkameez but fashion has changed the look of salwarkameez, in other words fashion with different sort of clothes has bring variation in traditional clothes.Television, internet, fashion shows, magazines all these are the mediums for introducing new trend, new fashion and new brands for people which gradually becomes part of their clothing (Walsh, Mitchell, Thurau, 2001, p. 73). According to David (2009) fashion was 
also in but not so, before the popularity of television; now each house has one or more than one TV, also has cable connection or dish which provide numerous fashion shows containing new dress designs which took the people in the world of glamour.

McClung \&Holdorf (n.d.) argues that clothes are the most important thing but in present era it cannot remain within one shape. They also have said that with the passage of time, somewhat fashion has made its place in culture; slowly and steadily people are accepting latest trend and want to know the updates about the upcoming fashion which mostly provided through the media because media set a trend for us through magazines, social media or television and in through television, fashion shows play a role of providing latest news regarding latest fashion.

Fashion exist in the culture and it adopt or modify culture; the process of adopt or modify culture start with radio, television, fashion shows, internet, social websites, newspaper, banners, billboards, advertisements or through magazines because people have to deal with these mediums several times in a day which leave impact on the outfits of people (Barnes, \& Greenwood, 2006, p. 261).

Today everyone wants to make his or her own identity because media is playing a role of teacher and creating a splendid image of ideal personality; to some extent media is succeed in this purpose because today television has become integral part of each home and children, teenagers, youth or adults have easy access to it; this access, in some way, portray their image as the persons who appear on TV screen and incentives them to adopt innovation in their clothes (Hamely, 2001).Television is a most viewing medium of mass media in Pakistan because Pakistan is a developing country where mostly people are illiterate; they can easily get knowledge and information by watching television; by taking the advantage of this, Indian and western countries move their culture, norms, values, custom, traditions, education and fashion towards the Muslim culture by using electronic media (Akbar, 2009)

According to Ahmad (2011)print and electronic media are the main mediums which give the way to fashion industry for changing our way of living by promoting branded items, apparels, footwear, jewelries and other accessories..No doubt media has made teenagers fashion conscious; teenage girls often try to shape their body, to make their identities, try to look beautiful by adopting different fabulous apparel and want to look a beauty with appear on the screen of television (Brandon 2011).

\section{Cultivation Theory}

This study has used the cultivation theory presented by George Gerbner for exploring the effect of fashion shows of TV channels on female students of UOG. According to this theory television hides the real truth and creates another world, which is considering a real world according to the viewers of TV.Gerbner argues that the medium of television is most watched, if anyone is regular watcher of television then television will cultivate a way of understanding the world (in his/her view), it will led him or her in the world of misunderstanding (Schiappa, 2008, p. 13). For example: If people mostly watch fashion shows on television, they must see a different style of dressing that may different from the clothes which he or she wears. After this he/she will think television always provide true information then which dressing style is broadcasting on it, it is right and which he or she wear, is not fit according to the television broadcasting. Then he or she will create another world, which misguide them. So television plays a role of story teller which tell a different story to different viewers, either the story is true or not (Facts, 2011).

Schiappa (2008, p. 13) says by watching more television bring change in the attitude of the viewers rather than the behavior. Television does not focally push the individual for accepting the change, it lightly pulls the individual for accepting and adopting the change; this light process change the attitude of the viewers towards the unreal world. Gerbner also says that this theory produce effects on levels, which are known as first order effects (learn facts from media) and second order effects (learn tentative answer about general believes from media) (Wikipedia, 2004).

\section{Methodological Design}

Fashion shows of TV channels directly or indirectly leave effects on the female students of UOG. This study will be conducted under the deductive approach because researcher has some tentative answers and want to prove them

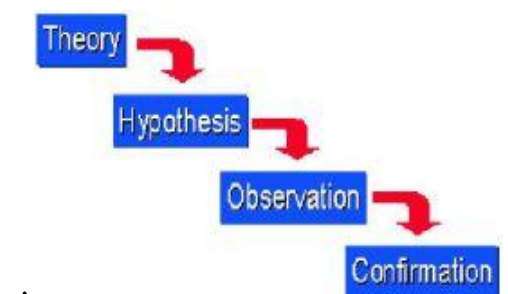

Figure 1 Deductive approaches - Waterfall (Malik, 2011) 


\section{Survey through Questionnaire}

Researcher has conducted a survey through questionnaire for collection data and testing hypothesis.

Target Audience: Researcher has selected University of Gujrat as a population and female students of UOG selected as a target audience.

Sample: In this research, researcher has specified the female students for research purpose and selected 150 female students as a sample.

Implication of Research: The findings of this research reveal that electronic media through fashion shows influences the individual dressing style and implement fashion apparel on individuals.

Data Collection and Analysis:The data was collected through questionnaire which randomly filled by the female students of University of Gujrat and analyzed by ssps

\section{Analysis \& interpretation}

Fashion shows, gradually, become necessary in our life. Sometimes its effects give a good and new look to our dresses and sometimes it's badly damage the image of our dressing style. Researcher was wanted to know how fashion shows of TV channel effects our dressing. For this research conduct a survey through questionnaire then analysis and interpret the data for rivaling the effects of fashion shows of TV channels on our dresses.

Q1: Where you live?

Graph 1: Information regarding living area of respondents

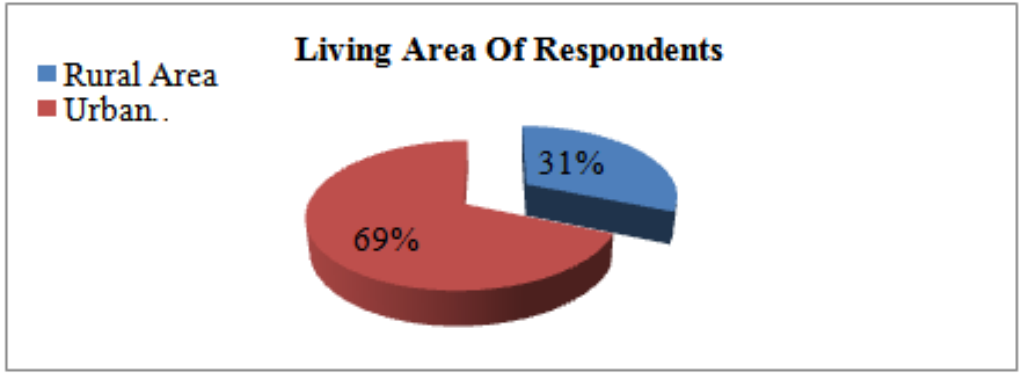

Graph 1 indicates that $69 \%$ respondents belong to urban area and $31.3 \%$ respondents belong to rural area. So it's concluded that mostly respondents belong to urban areas.

Q2: You belong to:

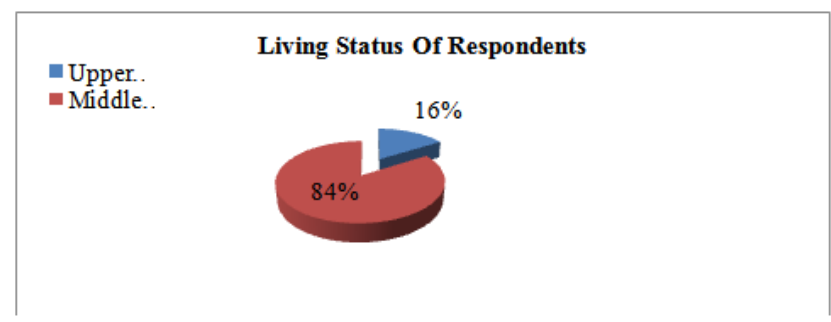

Graph 2: Information regarding living status of respondents

Q3: Your Monthly income is:

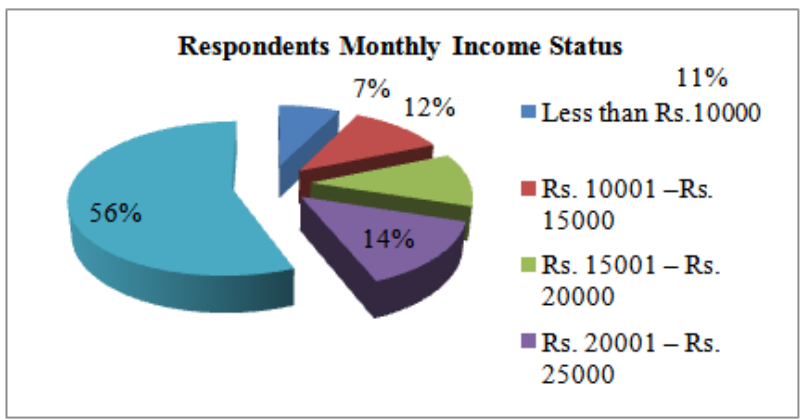

Graph 3: Information regarding monthly income of respondents 
Q4: In your view fashion is

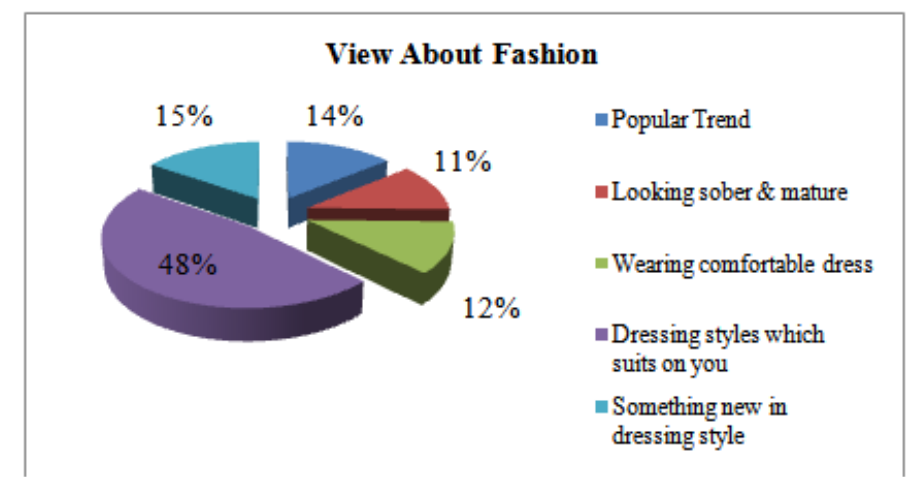

Graph 4: Information regarding the respondents views for fashion

Q5: Is fashion important to you? :

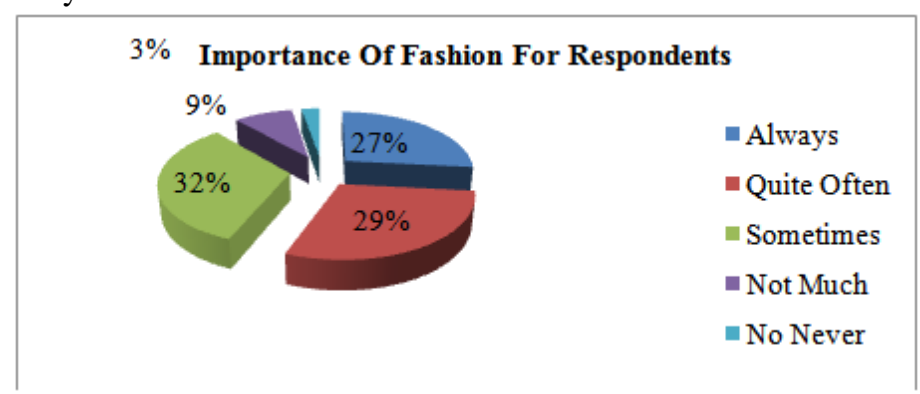

Graph 5: Information regarding the importance of fashion

Q6: Does fashion style inspire you by the TV fashion shows?

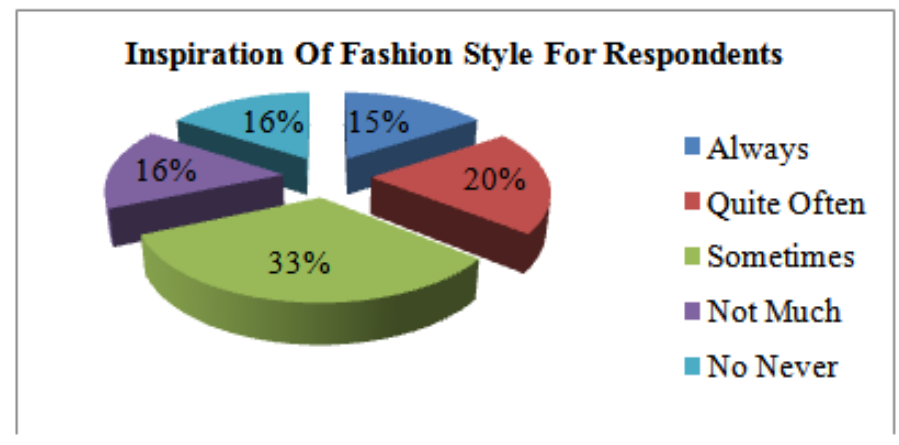

Graph 6: Information regarding the inspiration of fashion style for respondents

Q7: Do TV fashion shows help you for getting updates about latest fashion?

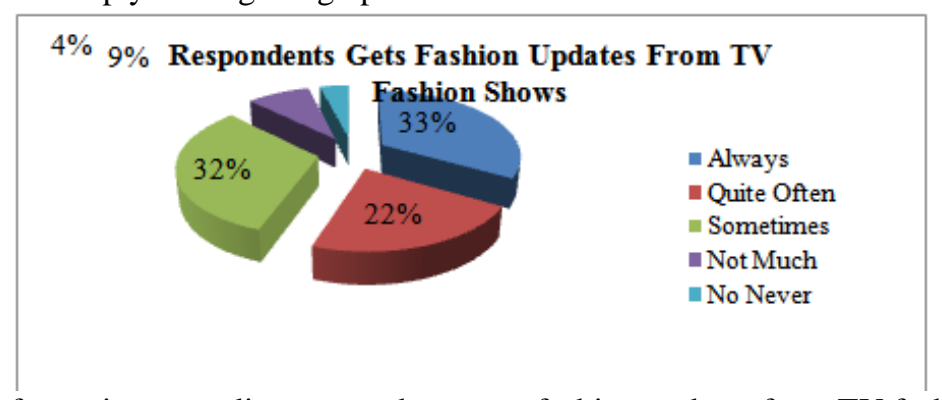

Graph 7: Information regarding respondents gets fashion updates from TV fashion shows Q8: Do you change your dressing according to the fashion? 


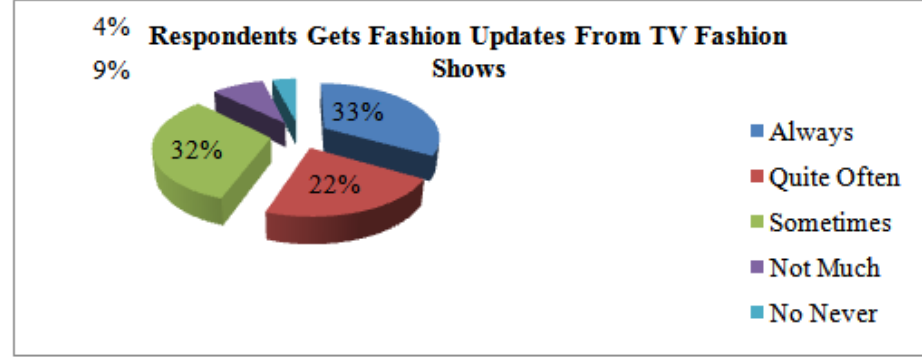

Graph8: Information regarding changing in dressing style according to fashion:

Q9: You change your dressing according to the fashion because:

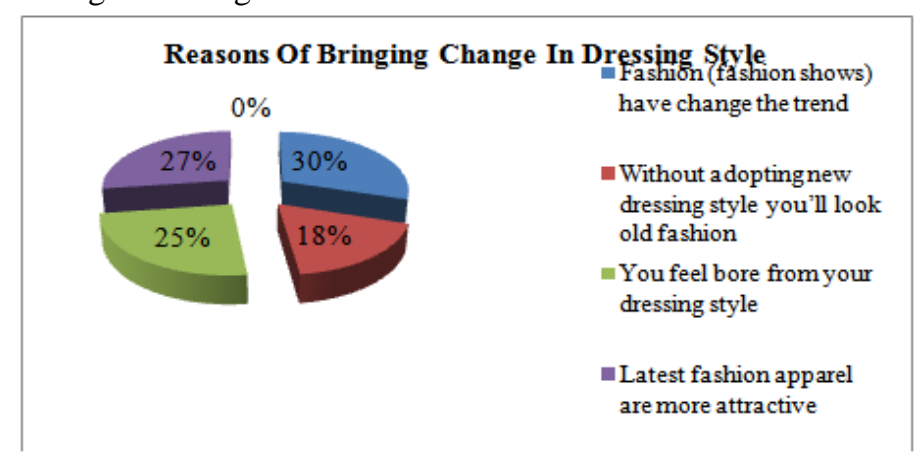

Graph 9: Information regarding the reason of bringing change in dressing style Q10: Do you want to be early adopter of latest fashion apparel

\section{Respondents Want To Be A First Follower}

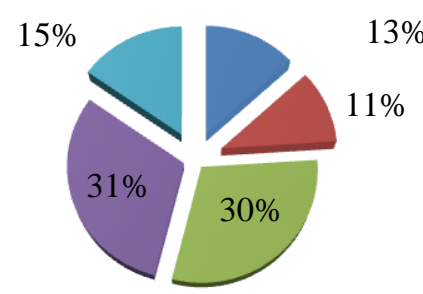

$$
\begin{aligned}
& \text { - Always } \\
& \text { Quite Often } \\
& \text { Somethimes } \\
& \text { Not Much } \\
& \text { No Never }
\end{aligned}
$$

Graph 10: Information regarding respondents wants to be a first follower of latest fashion

Q11: Do you fill your wardrobe with latest dress designs?

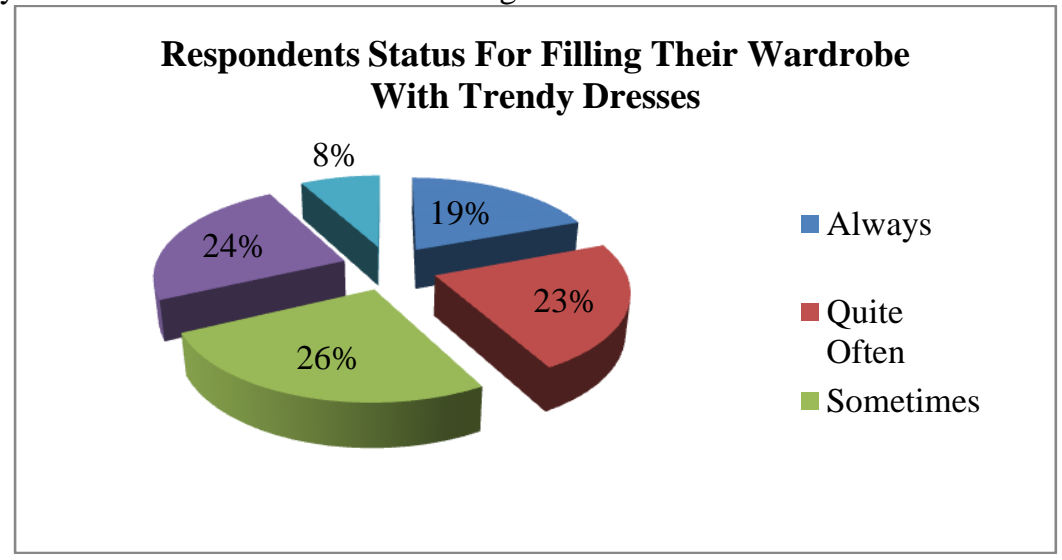

Graph 11: Information regarding respondents fills their wardrobe with latest fashion dresses 
Q12: When you purchase new dressing apparel?

\section{Respondents Purchasing New Dressing Apparel}
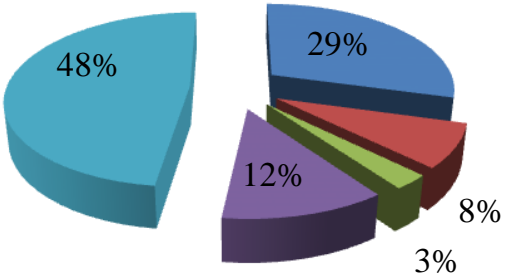

In every 3

months

In every 6

months

Once a year

Graph 12: Information regarding respondents purchasing status of new dressing apparel

Q13: In six months, how much do you like to spend on latest fashion apparel?

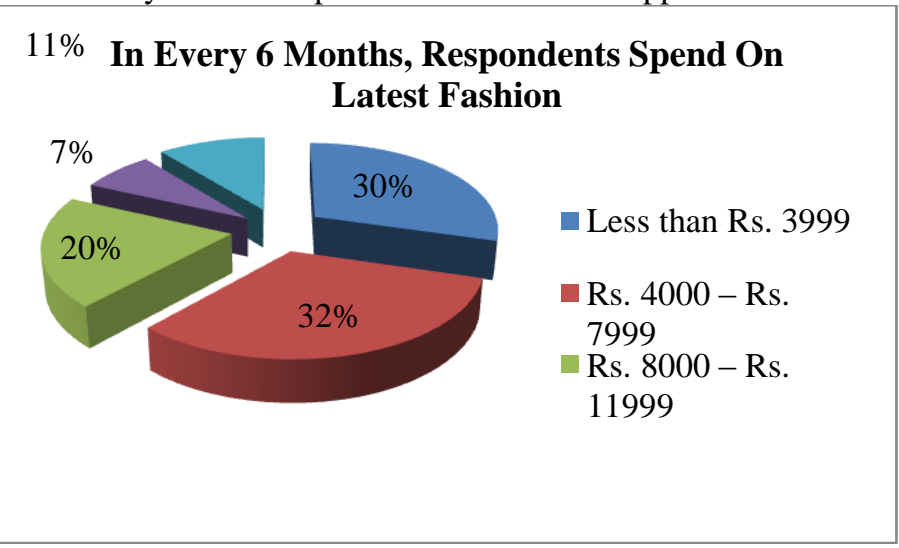

Graph 13: Information regarding respondent's expenditure on latest fashion dresses in six months

Q14: Do you inspire by the models of fashion shows on TV, wearing:

a) Indian Dresses (Saree)

Graph 14.1: Information regarding respondent's inspiration by Indian dresses wearing by the models of TV fashion shows

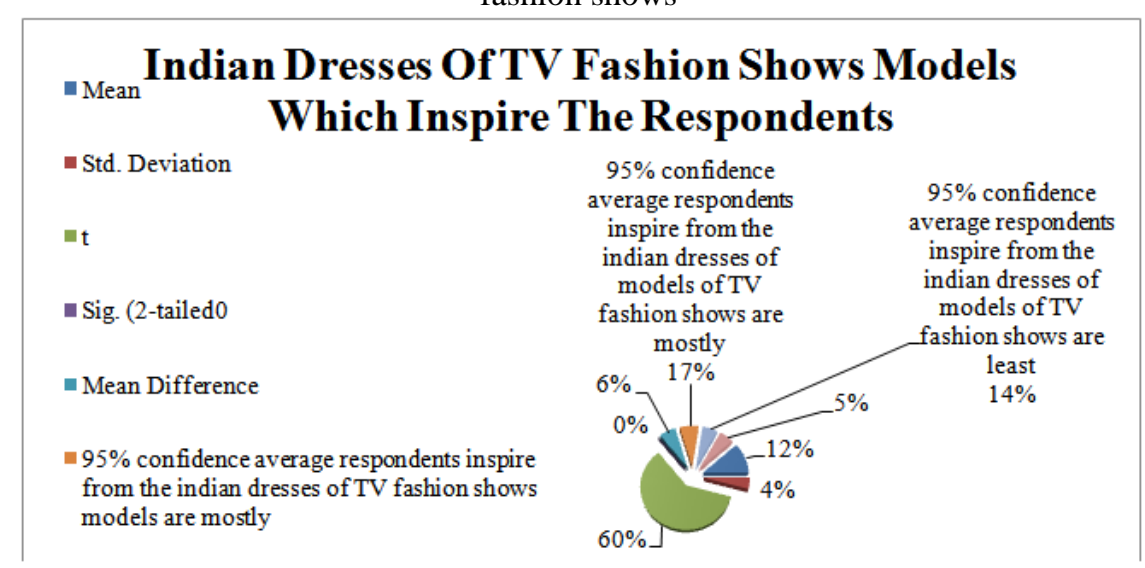

b)Indo-Western Dresses (Kurti, Shirts, Tops, Jeans)

Graph 14.2: Information regarding respondent's inspiration by indo-western dresses wearing by the models of TV fashion shows 


\section{Indo-Western Dresses Of TV Fashion - Mearhows Models Which Inspire The Respondents}

- Std. Deviation

Test Value

- $\mathrm{t}$

- Sig. (2-tailed)

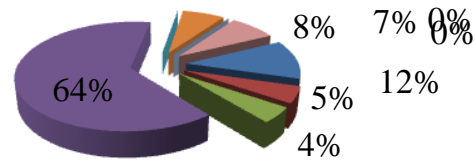

Graph 14.2 indicates the highly significant difference between the respondents who inspire from the Indo-

Western dresses wear by the models of TV fashion shows and who not inspire. It's also concluded that researcher $95 \%$ confidence about the average respondents inspire from the Indo-Western dresses wearing by models of TV fashion shows are mostly $17 \%$ above 100.

b) Latest Trendy Dresses (Churidar, Long Kameez, A-Line Kameez, Trouser)

Graph 14.3: Information regarding respondent's inspiration by latest trendy dresses wearing by the models of TV fashion shows

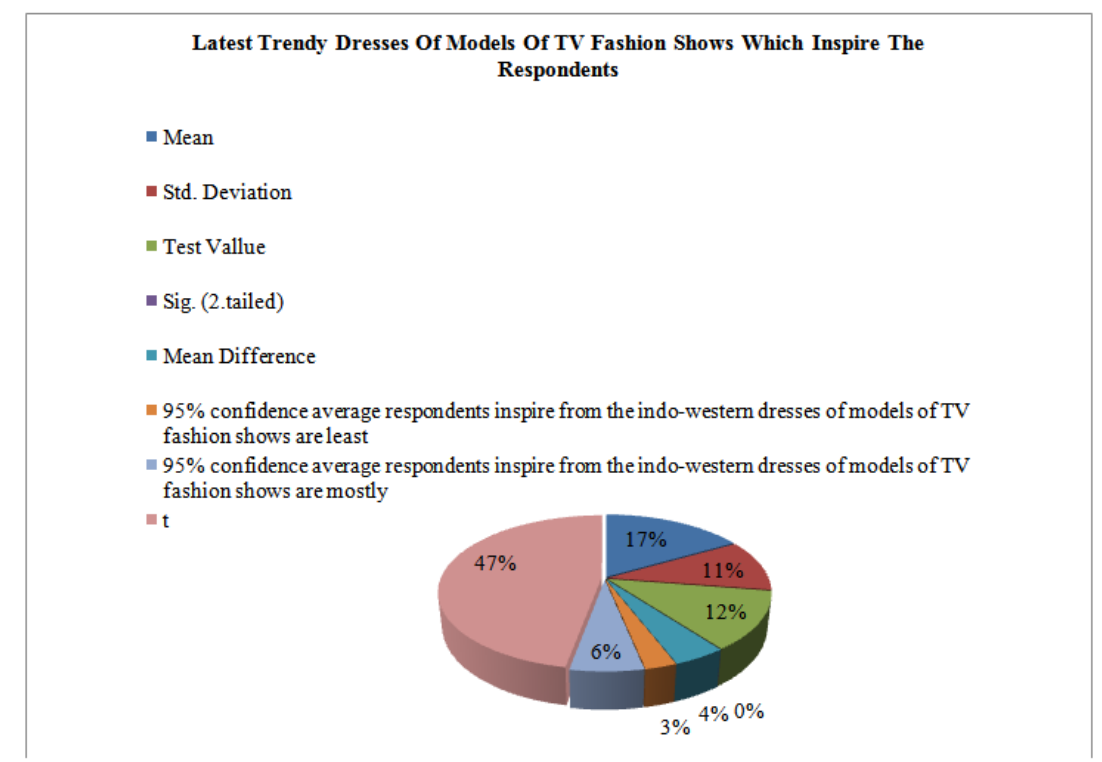

Graph 14.3 indicates the highly significant difference between the respondents who inspire from the latest trendy dresses wear by the models of TV fashion shows and who not inspire. It's also concluded that researcher 95\% confidence about the average respondents inspire from the latest trendy dresses wearing by models of TV fashion shows are mostly $6 \%$ above 100 .

Cultural Dresses (SalwarKameez)

Graph 14.4: Information regarding respondent's inspiration by cultural dresses wearing by the models of TV fashion shows 


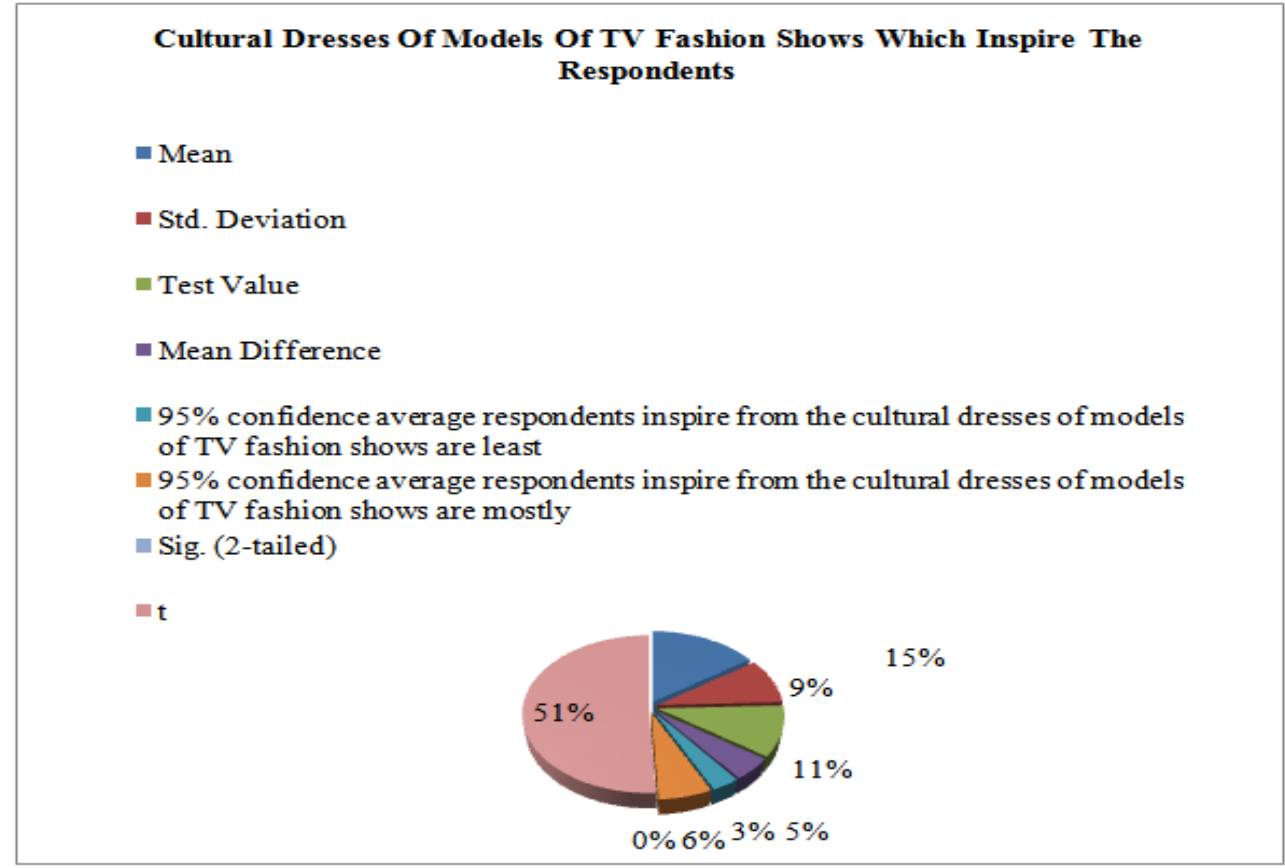

Graph 14.4 indicates the highly significant difference between the respondents who inspire from the cultural dresses wear by the models of TV fashion shows and who not inspire. It's also concluded that researcher 95\% confidence about the average respondents inspire from the cultural dresses wearing by models of TV fashion shows are mostly $6 \%$ above 100 .

Q15: On events respondents like to wear:

a) Indian Dresses (Saree)

Graph 15.1: Information regarding respondents wearing Indian dresses on events

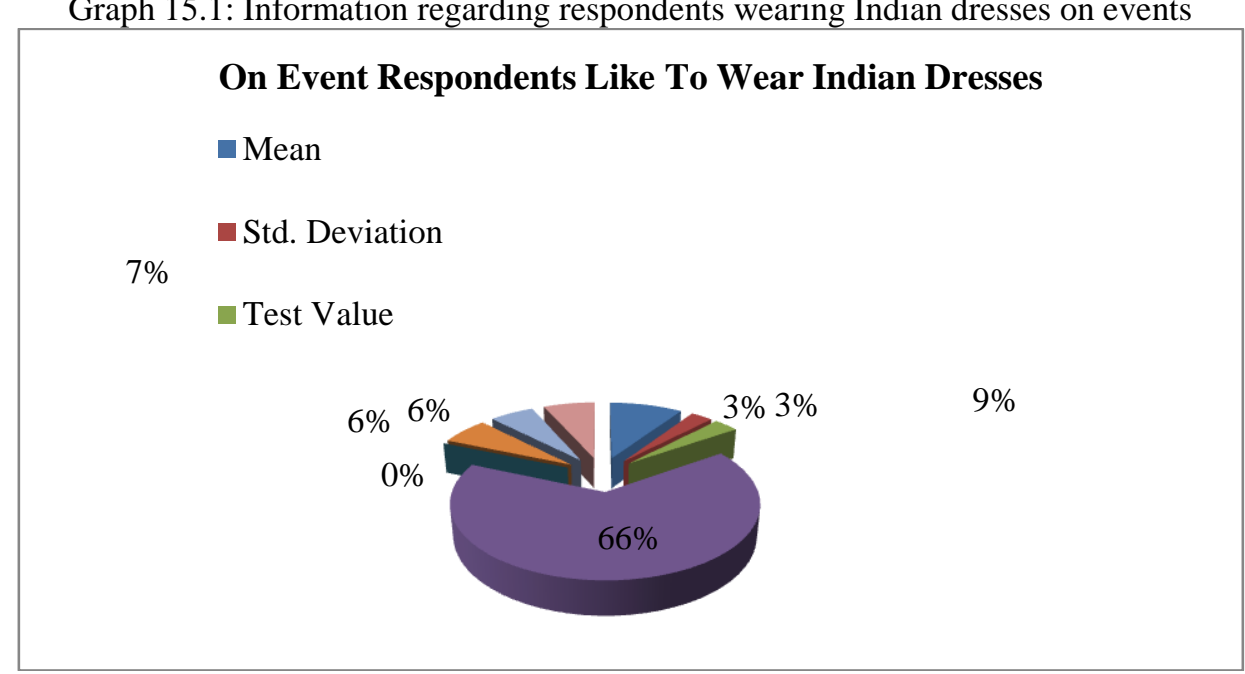

Graph 15.1 indicates the highly significant difference between the respondents who like to wear Indian dresses on the events and who don't like. It's also concluded that researcher $95 \%$ confidence about the average respondents wear Indian dresses on the events are mostly 7\% above 100.

b) Indo-Western Dresses (Kurti, Shirts, Tops, Jeans)

Graph 15.2: Information regarding respondents wearing indo western dresses on events 


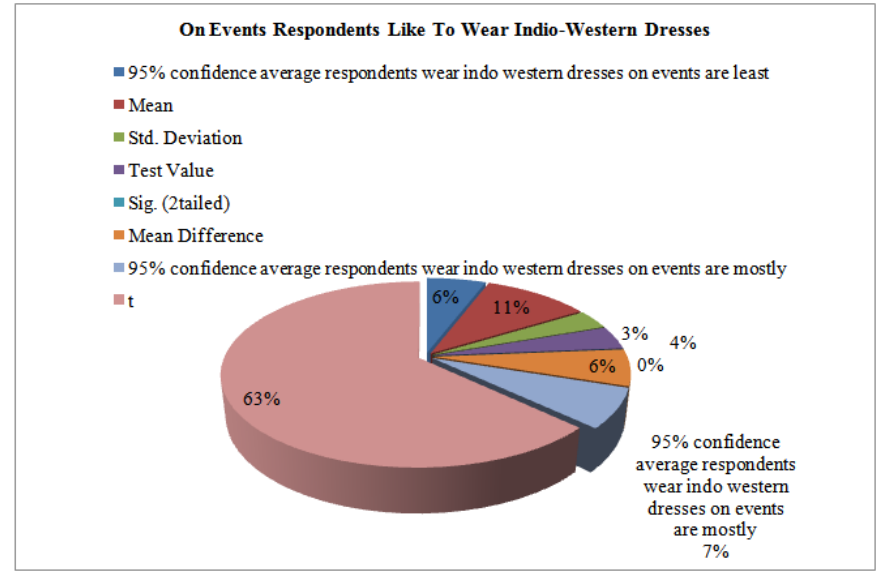

Graph 15.2 indicates the highly significant difference between the respondents who like to wear Indo western dresses on the events and who don't like. It's also concluded that researcher $95 \%$ confidence about the average respondents wear Indo western dresses on the events are mostly $7 \%$ above 100 .

c) Latest Trendy Dresses (Churidar, Long Kameez, A-Line Kameez, Trouser)

Graph 15.3: Information regarding respondents wearing latest trendy dresses on events

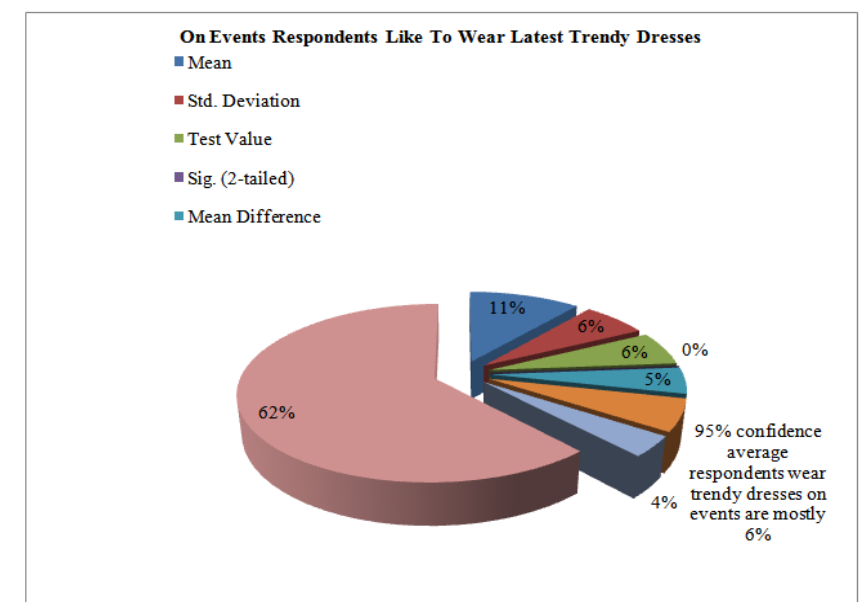

Graph 15.3 indicates the highly significant difference between the respondents who like to wear latest trendy dresses on the events and who don't like. It's also concluded that researcher $95 \%$ confidence about the average respondents wear Indian dresses on the events are mostly 7\% above 100.

c)Cultural Dresses (SalwarKameez)

Graph 15.4: Information regarding respondents wearing cultural dresses on events

\section{On Frentş Respondents Like To Wear Cultural Dresses}

- Std. Deviation

Test Value

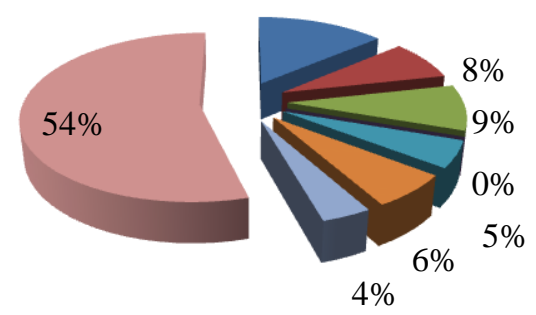

$14 \%$ 
Graph 15.4 indicates the highly significant difference between the respondents who like to wear cultural dresses on the events and who don't like. It's also concluded that researcher $95 \%$ confidence about the average respondents wear cultural dresses on the events are mostly $6 \%$ above 100 .

Q16: At home do you like to wear:

a) Indian Dresses (Saree)

Graph 16.1: Information regarding respondents wearing Indian dresses at home

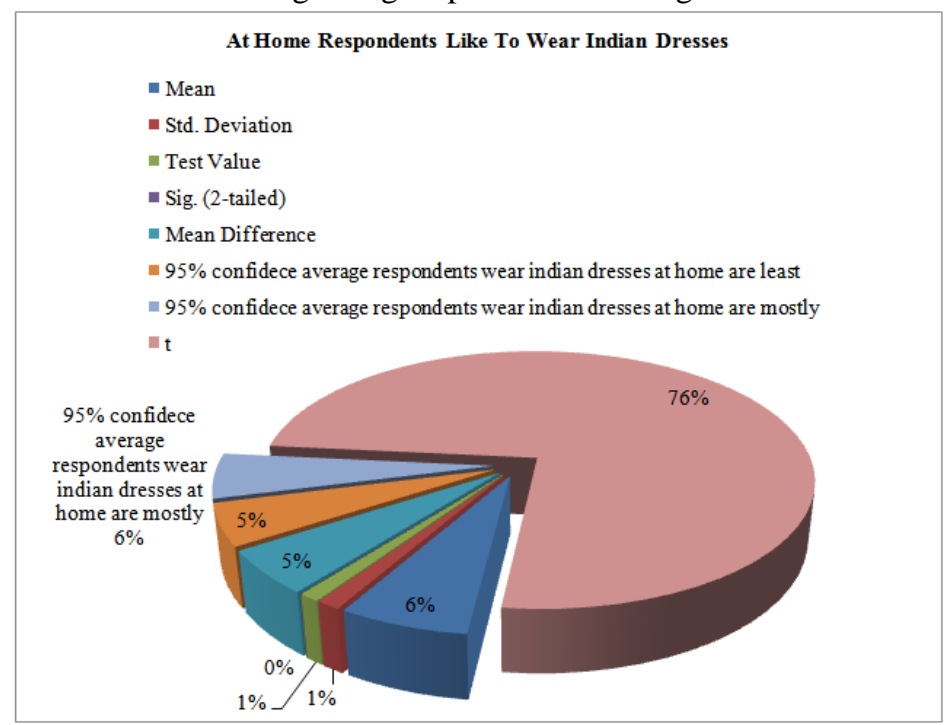

Graph 16.1 indicates the highly significant difference between the respondents who like to wear Indian dresses at home and who don't like. It's also concluded that researcher $95 \%$ confidence about the average respondents wear Indian dresses at home are mostly 6\% above 100.

b)Indo-Western Dresses (Kurti, Shirts, Tops, Jeans)

Graph 16.2: Information regarding respondents wearing Indian dresses at home

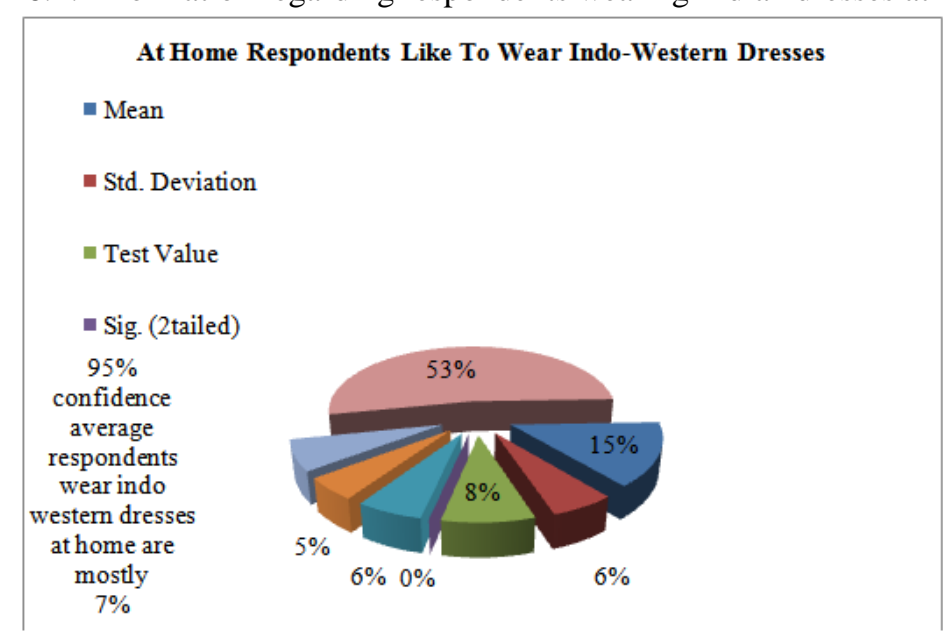

Graph 16.2 indicates the highly significant difference between the respondents who like to wear IndoWestern dresses at home and who don't like. It's also concluded that researcher $95 \%$ confidence about the average respondents wear Indo-Western dresses at home are mostly 7\% above 100.

b)Latest Trendy Dresses (Churidar, Long Kameez, A-Line Kameez, Trouser) 
Graph 16.3: Information regarding respondents wearing Indian dresses at home

\section{At Home Respondents Like To Wear Latest Trendy Dresses}

Mean

- Std. Deviation

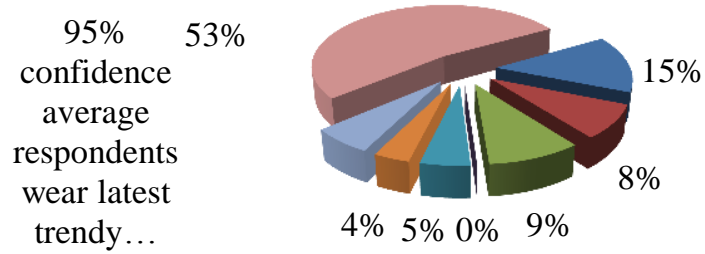

Graph 16.3 indicates the highly significant difference between the respondents who like to wear latest trendy dresses at home and who don't like. It's also concluded that researcher 95\% confidence about the average respondents wear Indian dresses at home are mostly 6\% above 100.

b)Cultural Dresses (SalwarKameez)

Graph 16.4: Information regarding respondents wearing cultural dresses at home

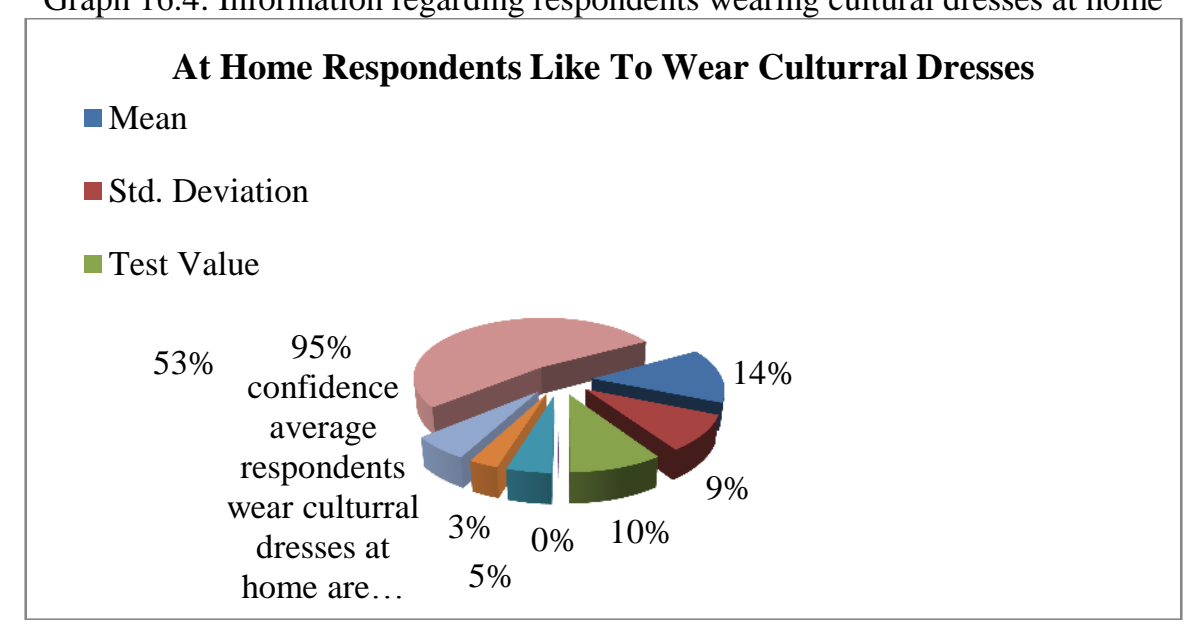

Graph 16.4 indicates the highly significant difference between the respondents who like to wear cultural dresses at home and who don't like. It's also concluded that researcher $95 \%$ confidence about the average respondents wear cultural dresses at home are mostly $6 \%$ above 100 .

Q17: In University, do you like to wear:

a) Indian Dresses (Saree)

Graph 17.1: Information regarding respondents like to wear Indian dresses in university

Mean

\section{In University Rspondents Wear Indian Dresss}

Std. Deviation

$95 \%$ confidence average respondents wear indian dresses in university are mostly...

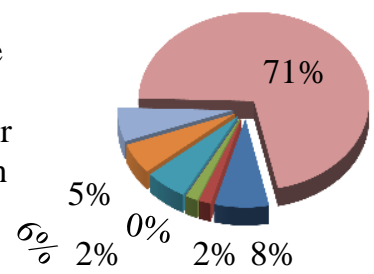


Graph 17.1 indicates the highly significant difference between the respondents who like to wear Indian dresses in university and who don't like. It's also concluded that researcher $95 \%$ confidence about the average respondents wear Indian dresses in university are mostly $6 \%$ above 100 .

b) Indo-Western Dresses (Kurti, Shirts, Tops, Jeans)

Graph 17.2: Information regarding respondents like to wear indo western dresses in university

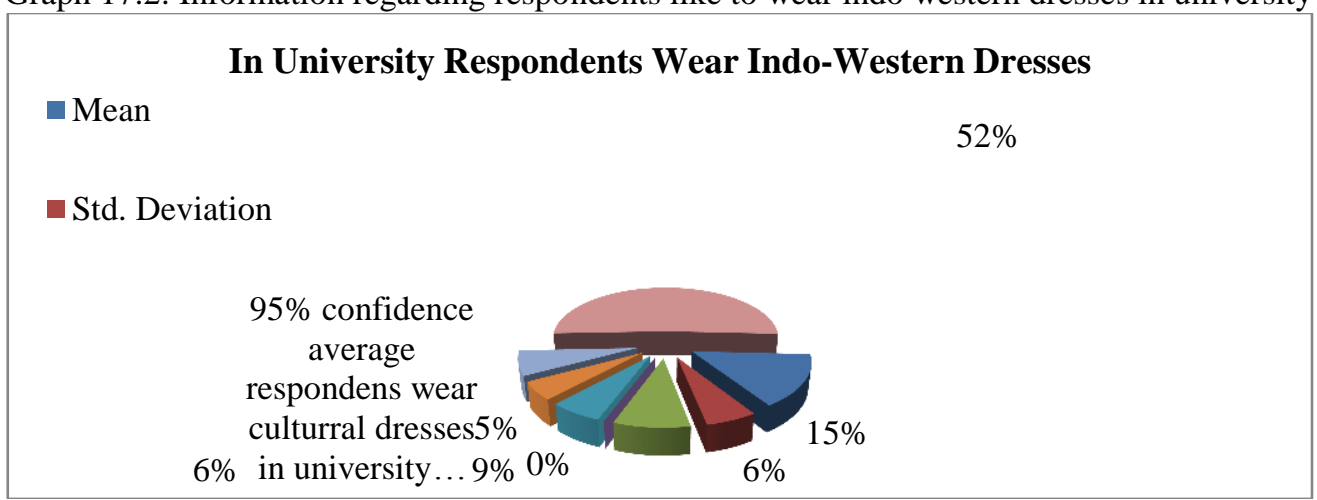

Graph 17.2 indicates the highly significant difference between the respondents who like to wear IndoWestern dresses in university and who don't like. It's also concluded that researcher 95\% confidence about the average respondents wear Indo Western dresses in university are mostly 7\% above 100 . c)Latest Trendy Dresses (Churidar, Long Kameez, A-Line Kameez, Trouser)

Graph 17.3: Information regarding respondents wearing latest trendy dresses in university

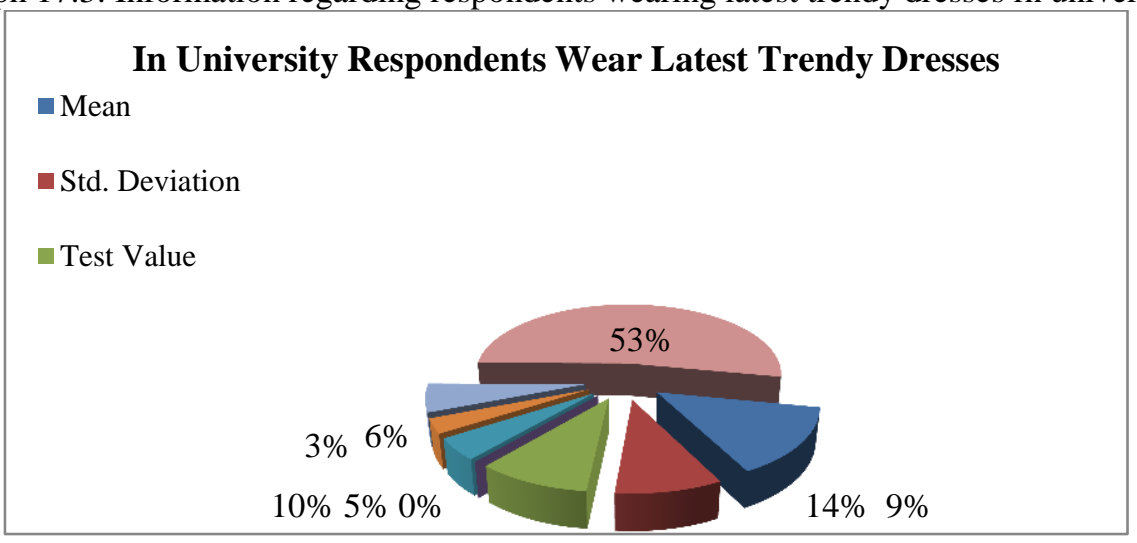

Graph 17.3 indicates the highly significant difference between the respondents who like to wear latest trendy dresses in university and who don't like. It's also concluded that researcher $95 \%$ confidence about the average respondents wear latest trendy dresses in university are mostly 6\% above 100 .

d)Cultural Dresses (SalwarKameez)

Graph 17.4: Information regarding respondents wearing cultural dresses in university

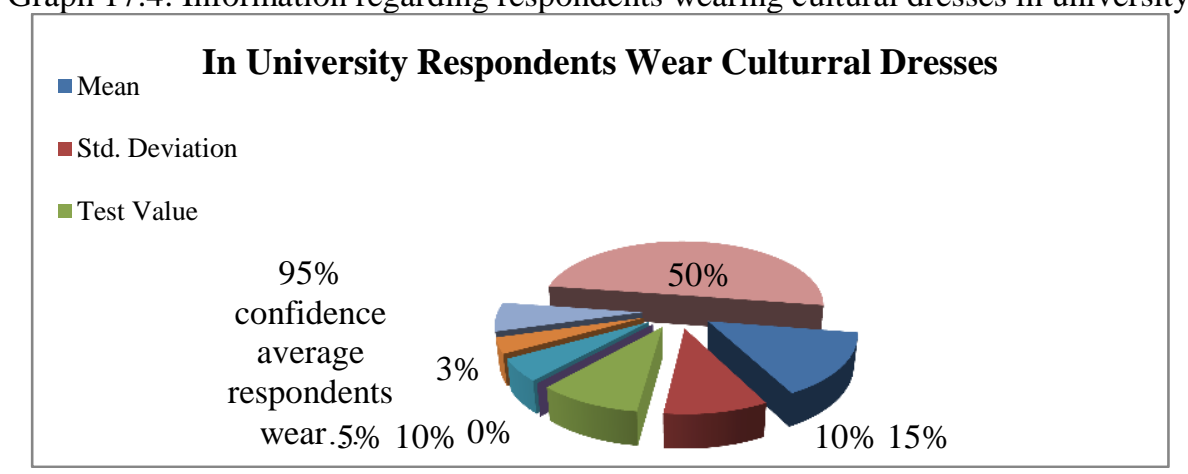


Graph 17.4 indicates the highly significant difference between the respondents who like to wear cultural dresses in university and who don't like. It's also concluded that researcher $95 \%$ confidence about the average respondents wear cultural dresses in university are mostly 7\% above 100 .

Q18: Which dress you would like to wear in routine life? (You can select more than one answer) Option 1: Indo-Western dresses (like Jeans, Kurti, Tops, Shirt, etc.)

Graph 18.1: Information regarding respondents wearing indo-western dresses in routine life

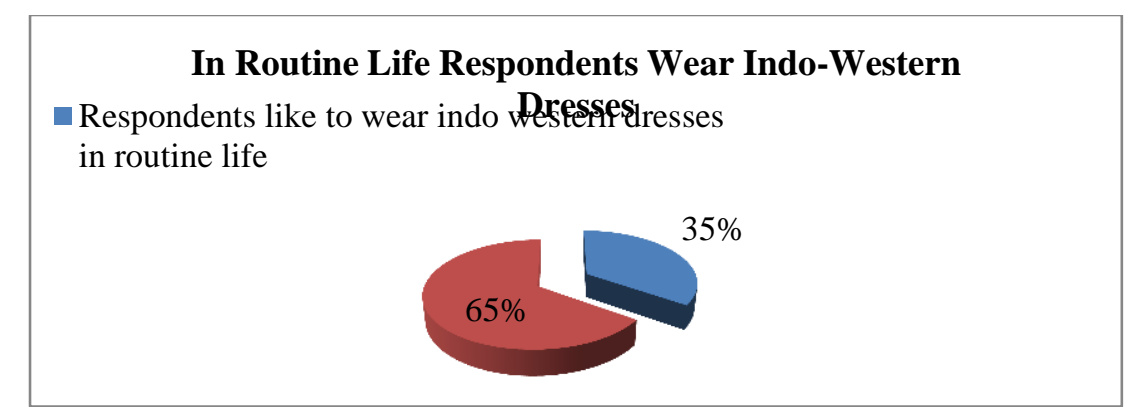

Graph 18.1 indicates that mostly $35 \%$ respondents like to wear western dresses and $65 \%$ respondents are not interested in wearing western dresses in their routine life. So it's concluded that a mostly respondents not wear western dresses in their routine life.

Option 2: Current Trendy Dresses (like A-Line, Churidar, Long Shirt, etc.)

Graph 18.2: Information regarding respondents wearing current trendy dresses in routine life

\section{In Routine Life Respondents Wear Current Trendy Dresses}

Respondents like to wear current trendy dresses

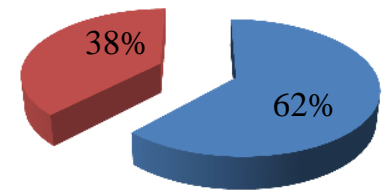

Graph 18.2 indicates that $62 \%$ respondents like to wear current trendy dresses and $38 \%$ respondents are not interested in wearing trendy dresses in their routine life. So it's concluded that mostly respondents like to wear trendy dresses in their routine life.

Option 3: Traditional Dresses (like SalwarKameez)

Graph 18.3: Information regarding respondents wearing traditional dresses in routine life

In Routine Life Respondents Like to Wear Traditional
Dresses
$\square$ Respondents like to wear traditional dresses
$\square$ Not intrested respondents

Not interested
respondents
$56 \%$


Graph 18.3 indicates that $44 \%$ respondents like to wear traditional dresses and $56 \%$ respondents are not interested in wearing trendy dresses in their routine life. So it's concluded that mostly people prefer to wear something other besides the traditional dresses.

Option 4: Contrast Of Western \& Pakistani Dresses (like long shirt with jeans)

Graph 18.4: Information regarding respondents wearing Western and Pakistani dresses in routine life

\section{In Routine LifeRespondents Wear Westren and \\ Pakistani Dresses}

Respondents wear contrast of western and pakistani dresses

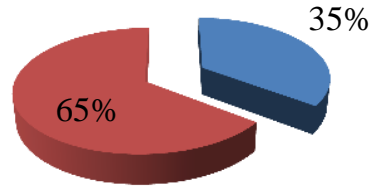

Graph 18.4 indicates that $35 \%$ respondents like to wear the combination of western and Pakistani dresses and 65\% respondents not feel any interest in wearing these dresses. So it's concluded that mostly respondents are not interested in the contrast of western and Pakistani dresses.

Option 5: Something in Which You Feel Comfortable

Graph18.5:Information regarding respondents wearing something in which they feel comfortable

\section{In Routine Life Respondents Wearing Something} Comfortable

- Respondents who were something in which they feel comfortable

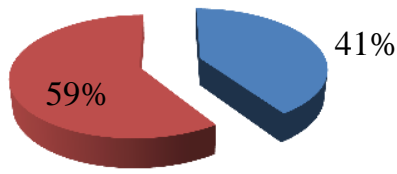

Graph 18.5 indicates that $41 \%$ respondents like to wear something in which they feel comfortable and $59 \%$ respondents don't feel interested in comfortable dresses. So it's indicates that mostly respondents prefer other dressing pattern on comfortable dresses.

Q19: Can you accept the latest fashion apparel appears on TV fashion shows?

Graph 19: Information regarding respondents who accept latest fashion from TV fashion shows

\section{Respondents Who Accept Latest Fashion From TV Fashion Shows}

Mean

- Std. Deviation

$\square$ Sig. (2-tailed)

- Mean Difference

-95\% confidence $95 \%$ confidence

average respondents acceptatest farom TV fashion shows are least

average respondents

accept latest fashion

from TV fashion

$3 \%$ shows are mostly $5 \%$

$6 \%$

$6 \% \quad 0 \% 3 \%$

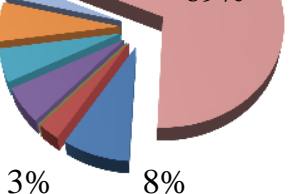


Graph 19 indicates the highly significant difference between the respondents who accept latest fashion from TV fashion shows and who don't like. It's also concluded that researcher $95 \%$ confidence about the average respondents accept latest fashion from TV fashion shows are mostly 6\% above 100.

Q20: Do the fashion shows of TV inspire you to experiment with new dressing style?

Graph 20: Information regarding respondent's inspiration and experiment with new dressing style through TV Fashion shows

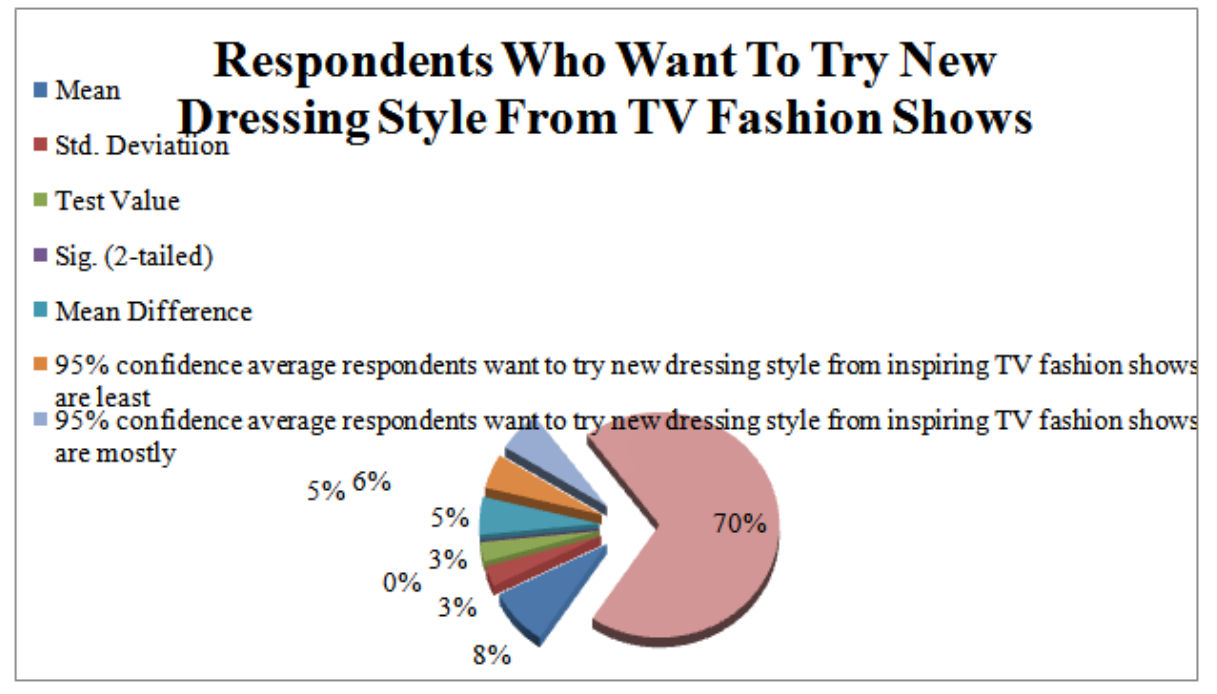

Graph 20 indicates the highly significant difference between the respondents who like to try new dressing style from inspiring TV fashion shows and who don't like. It's also concluded that researcher 95\% confidence about the average respondents who like to try new dressing style from inspiring TV fashion shows are mostly $6 \%$ above 100 .

Q21: Do Fashion shows play a good role by promoting new trend?

Graph 21: Information regarding respondents who says fashion shows play a good role by promoting new trend

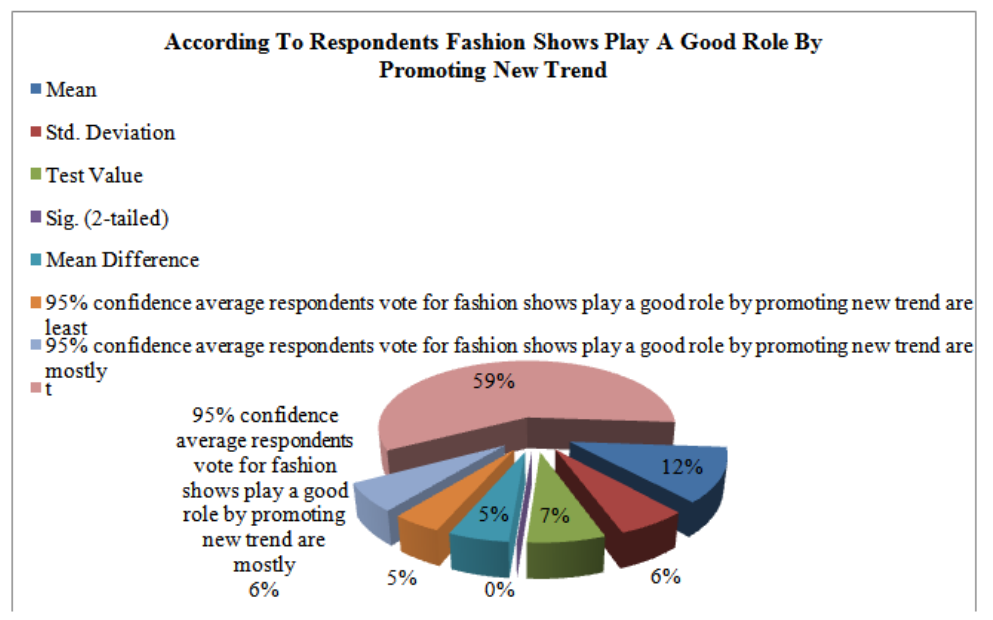

Graph 21 indicates the highly significant difference between the respondents who agree with fashion shows play a good role in promoting new trend and also indicates the alternative opinion of the respondents. It's also concluded that researcher $95 \%$ confidence about the average respondents agree with fashion shows play a good role in promoting new trend are mostly $6 \%$ above 100.

\section{Summary}

Media always play a role of an informative source. In beginning it provide limited sources of information and also it was limited with limited hands. It has also limited items and purposes. But with the passage of time it becomes demand of each home and every hand. No it is available in different types like radio, television, newspaper, magazines etc. All these types bring changes in the life of human beings. Mostly 
television is a necessary element of every home. Dish and cable provide a wide range of TV stations with verity of programs. Now a day's fashion shows on TV channels become popular among the viewers especially among the School Collegeand university girls because they want to live an up to date life with fashion. Fashion shows on TV channels are a great source for such purpose. It provides all the necessary information regarding fashion apparels, fashion designs or current fashion trend without going anywhere. This facility has made the girls crazy for fashion. This fond of fashion has changed the dressing style of young girls and also made them agree for adopting western dresses. Researcher conducts this research for finding the answers of some questions and for measuring the influence or effects of fashion on the girls dressing style. For this purpose researcher randomly select 150 samples of female students of University of Gujrat. Researcher adopts a survey methodology and selects a questionnaire as a measuring instrument. For analysis Findings

1. $69 \%$ respondents belong to urban area while $31 \%$ respondents belong to rural area (Graph1, p.19). $84 \%$ respondents belong to middle class while $16 \%$ respondents belong to upper class (Graph 2, p.20). Income status of 56\% respondents is more than Rs. 25000 and only 7\% respondents is Less than Rs. 10000 (Graph 3 , p.21). It indicates that mostly respondents belong to urban area and mostly respondents also belong to middle class and mostly respondents have more than Rs. 25000 monthly incomes.

2. $48 \%$ respondents said fashion is a dressing style which suits on you, $15 \%$ respondents said fashion is something new in dressing style and $11 \%$ respondents said; fashion is looking sober \& matures (Graph 4 , p. 22) but $33 \%$ respondents always get fashion updates from TV fashion shows, $32 \%$ sometimes get fashion updates from TV fashion shows and only $4 \%$ respondents not get fashion updates (Graph 7, p. 25). It indicates that mostly respondents get fashion updates because they thought current fashion is suits on them.

3. $14 \%$ respondents always inspire from the fashion, $33 \%$ respondents sometime inspire from the fashion and $16 \%$ respondents never inspire from the fashion. $29 \%$ respondents always gave importance to fashion, $32 \%$ respondents sometime gave importance to fashion while only $3 \%$ respondents never gave importance to fashion (Graph 5, p. 23). It indicates that mostly respondents sometime inspire from the fashion and gave importance to fashion.

4. $29 \%$ respondents purchase new dresses in every 3 months while $48 \%$ respondents purchase dresses whenever necessary (Graph 12, p. 30). 32\% respondents spend Rs. 4000 - Rs. 7999 while $7 \%$ respondents spend Rs. 12000 - Rs. 15000 in every 6 months for purchasing latest dresses (Graph 13, p. 31). It indicates that mostly respondents purchase latest dresses whenever necessary and mostly respondents spend Rs. 4000 - Rs. 7999 on their dresses.

5. $34 \%$ respondents always change their dressings according to the fashion, $32 \%$ respondents sometimes change their dressing according to the fashion and only 3\% respondents not change their dressing according to fashion (Graph 8, p. 26). Because 30\% respondents believe fashion (fashion shows) have change the trend, $18 \%$ respondents believe without adopting new dressing style you'll look old fashion (Graph9, p. 27). It indicates that mostly respondents change their dressing with the fashion because fashion has changed the trend.

6. $31 \%$ respondents not much want to be a first follower, $30 \%$ respondents sometimes want to be a first follower and $13 \%$ respondents always want to be a first follower (Graph 10, p. 28) while $26 \%$ respondents sometimes want to fill their wardrobe with trendy dresses, $24 \%$ not much fill their wardrobe with trendy dresses and 19\% always fill their wardrobe with trendy dresses (Graph 11, p. 29). It indicates that some respondents always want to be a first follower of fashion and fill their wardrobe with trendy dresses and sometimes some respondents want to be a first follower of fashion and fill their wardrobe with latest dresses.

7. $17 \%$ respondents inspire from the models of TV fashion shows who wearing latest trendy dresses, $12 \%$ respondents inspire from the models of TV fashion shows who wearing latest trendy dresses, $14 \%$ respondents inspire from the models of TV fashion shows who wearing latest trendy dresses and 15\% respondents inspire from the models of TV fashion shows who wearing latest trendy dresses (Graph14.114.4, p. 32-35). It indicates that mostly respondents inspire from the other dresses instead of the Cultural dresses.

8. $9 \%$ respondents like to wear Indian dresses on events, $11 \%$ respondents like to wear indo western dresses on events, $11 \%$ respondents like to wear trendy dresses on events and $14 \%$ respondents like to wear cultural dresses on events (Graph15.1-15.4, p. 36-39). It indicates that a big part of new generation move towards other dressing style and few respondents still wear cultural dresses on events.

9. $6 \%$ respondents like to wear Indian dresses at home, $15 \%$ respondents like to wear indo western dresses at home, $15 \%$ respondents like to wear trendy dresses at home and $14 \%$ respondents like to wear cultural dresses at home (Graph 16.1-16.4, p. 40-43). It indicates that wearing indo western dresses and latest trendy dresses become the preference of respondents at home. 
10. $8 \%$ respondents like to wear Indian dresses in university, $15 \%$ respondents like to wear indo western dresses in university, $14 \%$ respondents like to wear trendy dresses and $15 \%$ respondents like to wear cultural dresses in university (Graph 17.1-17.4, p. 44-47). It indicates that indo western dresses become a competitive of cultural dresses.

11. $62 \%$ respondents like to wear trendy dresses in routine life, $44 \%$ respondents like to wear traditional dresses in routine life $41 \%$ respondents like to wear something comfortable and $35 \%$ respondents like to wear indo western dresses and $35 \%$ respondents like to wear combination of western and Pakistani dresses in their routine life (Graph 18.1-18.5, p. 48-52). It indicates that respondents like to adopt the fashion of trendy dresses in their routine life.

12. $8 \%$ respondents accept the latest fashion apparel for the TV fashion shows (Graph 19, p.53), 8\% respondents want to trying new dressing style from TV fashion shows (Graph 20, p.54) and $12 \%$ respondents said fashion shows play a good role by promoting new trend (Graph 21, p.55). It indicates that respondents like fashion shows of TV channels, they also accept the latest fashion and also try to follow them.

\section{Conclusion}

According to the findings, the following conclusion has drawn by the researcher.

Mostly respondents live in urban area and belong to the middle class family. And mostly respondents have more than Rs. 25000 monthly incomes. They spend Rs.4000 to Rs. 7999 in every 6 months for the latest trendy dresses. 33\% respondents always get updates about fashion from TV fashion shows while a small part of respondents always get updates about fashion from TV fashion shows. Moreover, the trendy dresses have modified the shape of cultural dresses and both trendy and western dresses have gain importance among the youth of female students.

\section{Recommendations:}

TV fashion shows must want to promote such dressing styles which can build up the image of Islam and Pakistani culture. These TV fashion shows can help to build up the personality of female students of school, college or universities. So these TV fashion shows don't only try to spread the wrong way of fashion.

\section{References}

[1]. Ahmad, G. (2011). What is importance of fashion [hub post]. Retrieved from http://gulnazahmad.hubpages.com/hub/Importance-ofFashion

[2]. Akbar, M., W. (2009). Cultural invasion of western media and Muslim societies.Global media journal - Pakistan edition, 2(2). Retrievedfrom Http://Www.Aiou.Edu.Pk/Gmj/Cultural\%20invasion\%20of\%20western\%20media\%20and\%20muslim\%20societies4.Asp

[3]. Baloch, S. (2011, August 26). Role of television.InPakistan Today. Retrieved June 23, 2012, from http://www.pakistantoday.com.pk/2011/08/26/comment/editors-mail/role-of-television/

[4]. Barnes, L., \& Greenwood, G., L. (2006). Fast fashioning the supply chain: shaping the research agenda. Journal of fashion marketing and management, 10(3), 261.doi:10.1108/13612020610679259

[5]. Berger, C. (n.d.). How style television shows and fashion magazines affect the way women dress [Blog post]. Retrieved from http://womenpartner.org/blog/2011/11/07/how-style-television-shows-and-fashion-magazines-affect-the-way-women-dress/

[6]. Brandon, M. (2011, October 2). Media influence teenagers. In Examiner.com. Retrieved June 23, 2012, from http://www.examiner.com/article/how-the-media-influences-teenagers

[7]. Characteristics of television as a medium.(n.d.).Role of television as a mass medium, 17. Retrieved from https://docs.google.com/viewer?a=v\&q=cache:sWo4D25R01kJ:download.nos.org/srsec335new/ch14.pdf+role+of+television+as+a +mass+medium\&hl=en\&gl=pk\&pid=bl\&srcid=ADGEESjk3agtzBZGPDWGhau1Gs6EnXbdFUOGyTQjTNwxS

[8]. Characteristics of television as a medium.(n.d.).Role of television as a mass medium, 18. Retrieved from https://docs.google.com/viewer?a=v\&q=cache:sWo4D25R01kJ:download.nos.org/srsec335new/ch14.pdf+role+of+television+as+a +mass+medium\&hl=en\&gl=pk\&pid=bl\&srcid=ADGEESjk3agtzBZGPDWGhau1Gs6EnXbdFUOGyTQjTNwxS

[9]. Crane, D. (2000). Fashion, identity, and social change. In Fashion and its social agendas: class, gender, and identity clothing (p. 1). London: University $\quad$ of $\quad$ Chicago $\quad$ Press. $\quad$ Retrieved from http://books.google.com.pk/books?hl=en\&lr=\&id=vphcHONAXmwC\&oi=fnd\&pg=PR9\&dq=influence+of +fashion+on+female+ap parel\&ots=qcL5AqYEMV\&sig=LxksqZcnOUhvcH_HquTGWpSjRic\#v=onepage\&q=influence\%20of $\% 20$ fashion $\% 2$

[10]. Cultivation theory.(2004). In Wikipedia, the free encyclopedia. Wikimedia Foundation, Inc. Retrieved June 24, 2012, from http://www.enotes.com/topic/Cultivation_theory

[11]. David, D. (2009, July 15). Role of television in fashion industry: positive \& negative effects. A community of people who love to write. Retrieved from http://www.saching.com/Article/Role-of-television-in-fashion-industry--Positive---Negative-effects/3104

[12]. Fashion show lighting.(n.d.).In Wikipedia. Retrieved June 23, 2012, from http://en.wikipedia.org/wiki/Fashion_show_lighting\#Purpose
Fashion [Definition]. $\quad(2010 \quad$ ). In Oxford
dictionaries. http://oxforddictionaries.com/definition/fashion?q=fashion

[14]. Fashion.(n.d.).In Wikipedia. Retrieved June 23, 2012, from http://en.wikipedia.org/wiki/Fashion

[15]. Gerbner and cultivation theory. (2011, November 28). In The glaring facts. Retrieved June 23, 2012, from http://www.theglaringfacts.com/communications/comm-theories/gerbner-cultivation-theory/

[16]. Hamley, K. (2001, April). Media use in identity construction. Retrieved June 22, 2012, from www.google.com.pk/url?sa=t\&rct=j\&q=media behaviour towards fashion 
portray\&source=web\&cd=3\&ved=0CF8QFjAC\&url=http://www.aber.ac.uk/media/Students/klh9802.html\&ei=jBvkT8awK6zZ4QS Jn-DCCA\&usg=AFQjCNGshz2

[17]. Kiran, A., Riaz, A., \& Malik, N., H. (2002). Factors affecting change in the clothing patterns of the adolescent girls. International Journal of Agriculture \& Biology, 4(3), 378. Retrieved from http://www.fspublishers.org/ijab/pastissues/IJABVOL_4_NO_3/21.pdf

[18]. Malik, H., R. (Hub writer). (2011). Deductive approach.[Hub Photo]. Retrieved June 24, 2012, from http://hafeezrm.hubpages.com/hub/Types-of-Research

[19]. Mass Media [Definition]. (n.d.).Retrieved June 7th, 2012, from http://www.yourdictionary.com/mass-media

[20]. McClung, S., \&Holdorf, R. (n.d.). The role of teen oriented fashion magazine content on clothing purchasing behaviors and attitudes of adolescents and teens. Retrieved June 20, 2012, https://docs.google.com/viewer?a=v\&q=cache:8Y6WvkJX64sJ:www.cbs.dk/content/download/41834/616339/file/Paper\%252016_ Steven\%2520McClung_Rebecca\%2520Holdorf.pdf+The+Role+of+Teen+Oriented+Fashion+Magazine

[21]. Mcdermott, R., J., \& Albrecht, T., L. (2002).Mass media. Encyclopedia of PublicHealth. 2002. Retrieved June 22, 2012, from Encyclopedia.com: $\quad$ http://www.encyclopedia.com/doc/1G2-3404000519.html

[22]. McFatter, R., D. (2005, May).Fashion involvement of affluent female consumers. $\begin{array}{llll}\text { University and Agricultural and Mechanical College). Raster's thesis, Louisiana State } & \text { Retrieved from }\end{array}$ 01242005143159/unrestricted/McFatter_thesis.pdf

[23]. Media [Definition]. (April, 2010). In Oxford dictionaries.Retrieved June 22, 2012, Oxford University Press: http://oxforddictionaries.com/definition/media

[24]. Media in fashion.(n.d.).In Sidewalksarerunways.com. Retrieved June 21, 2012, from http://www.sidewalksarerunways.com/anarticle-explaining-details-about-the.html

[25]. Meir, G. (n.d.). BrainyQuote.com. Retrieved June 22, 2012, from BrainyQuote.com. Website: http://www.brainyquote.com/quotes/quotes/g/goldameir102183.html

[26]. Murray, L. (Blog writer). (2010, September 27). Cultivation Theory Model. [Blog Photo]. Retrieved June 24, 2012 fromhttp://4.bp.blogspot.com/_wu2MTGqtCe4/TJJMCSVaeqI/AAAAAAAAABo/Cnj2tcXyYU/s400/picture_gerbner_cultivation_t heory.bmp

[27]. Nirmala. (2008, November 3). Fashion history.InSlideshare. Retrieved June 23, 2012, from http://www.slideshare.net/Annie05/fashion-history-presentation-716164

[28]. Noubikko.(n.d.).In Noubikko. Retrieved June 22, 2012, from http://www.noubikko.com/noubikkobody/tips/advise/whatfashion.htm

[29]. Porter, H., M. (n.d.).Watching buffy: an angian examination of buffy watchers. Retrieved June 22, 2012, from https://docs.google.com/viewer?a=v\&q=cache:3cgLgDYNHQ0J:slayageonline.com/SCBtVS_Archive/Talks/Porter.doc+\&hl=en\&g l=pk\&pid=bl\&srcid=ADGEESiCKbuxFYXRKjciO47cX8b8eUlyoN6GGrNLTil6yhmipkr9QzpH31V7c6bdfa6c

[30]. Schiappa, E. (2008). The impossible dream of representational correctness. In Beyound representational correctness: rethinking criticism of popular media (p. 13). New York, NY: State University of New York Press, Albany. Retrieved from http://books.google.com.pk/books?id=WyZKNP2hMucC\&pg=PA13\&dq=george+gerbner+cultivation+theory+summary\&hl=en\&s

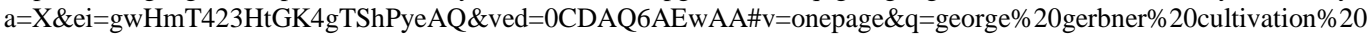

[31]. Walsh, G., Mitchell, V., W, \&Thurau, T., H. (2001).German consumer decision making styles. The Journal Of Consumer Affairs, 35(1), 73. Retrieved from http://www.marketingcenter.de/lmm/research/publications/download/I3_Walsh_Mitchell_HennigThurau_JCA_2001.pdf

[32]. Zeb, H., Rashid, K., \& Bilal, M., J. (2011). Influence of brands on female consumer's buying behavior in Pakistan. International Journal of Trade, Economics and Finance, 2(3), 225. Retrieved from http://www.ijtef.org/papers/107-F504.pdf 